Int. J. Appl. Radiat. Isot. Vol. 35, No. 12, p. $1133,198+$ C Pergamon Press Lid 1984. Printed in Great Britain. $0020-708 \times 84 \$ 3.00+0.00$

\section{Salicylamide-a Novel Solute for Liquid Scintillation Counting}

\section{J. GEBICKI, W. REIMSCHÚSSEL and J. RUDZINSKI}

Institute of Applied Radiation Chemistry, Technical University, Wróblewskiego 15, 90-924 Lodz. Poland

(Received 2 March 1984; in revised form 4 May 1984)

It is well established that some hydrogen bonded chelates undergo proton transfer in the singlet excited state resulting in a significantly red-shifted emission band. (1.2) The quantum yield of this fuorescence is generally low, but there are known examples in which it is fairly large, for example in the case of salicylamide. ${ }^{\mid 3 !}$

Salicylamide is chemically stable and has very good radiation and photochemical stability. The fluorescence of salicylamide, with a maximum about $430-440 \mathrm{~nm}$, overlaps the region of maximum sensitivity of photomultipliers used in commercial liquid scintillation counters. The large Stoke's shift together with the very low cost (10-30 times lower than typical scintillators currently available on the market) inspired us to investigate this compound as a potential scintillator in liquid scintillation counting.

An Intertechnique SL30 liquid scintillation counter was used for radioactivity determination. Based upon the solubility as well as the energy transfer properties, $p$-xylene, alone or as a mixture with dioxane, was chosen as a solvent. For these solvents the optimum concentration of salicylamide varied between 2 and $3 \mathrm{~g} / \mathrm{L}$. Counting efficiencies in the vicinity of $75 \%$ were easily achieved for solutions of salicylamide in $p$-xylene containing a ${ }^{14} \mathrm{C}$-labelled standard. The addition of up to $5 \%$ water by volume to the salicylamide solution $(3 \mathrm{~g}, \mathrm{~L})$ in the mixed solvent ( $p$ xylene-dioxane-ethanol, 8:2:5) caused a small decrease in
Table 1 . Counting efficiency (in $\%$ ) of a ${ }^{36} \mathrm{Cl}$-labelled standard in solutions of salicylamide and salicylic acid at a concentration $2 \mathrm{~g} / \mathrm{L}$ in various solvents

\begin{tabular}{lcc}
\hline \multicolumn{1}{c}{ Solvent } & Salicylamide & Salicylic acid \\
\hline water & 5.5 & 5.7 \\
DMSO & 15.5 & 12.2 \\
acetone & 34.3 & 20.0 \\
dioxane & 68.6 & 40.3 \\
p-xylene & 77.8 & 73.2 \\
p-xylene-dioxane (3:2) & 96.0 & 90.3 \\
\hline
\end{tabular}

the counting efficiency for ${ }^{1+} \mathrm{C}$, from about $50 \%$ to about $40 \%$.

Other experiments showed that a scintillation cocktail containing $3 \mathrm{~g}$ salicylamide/L pius $1-2 \mathrm{~g}$ butyl-PBD/L in $p$-xylene yielded the same counting efficiency for ${ }^{4} \mathrm{C}$, about $90^{\circ}$, as a pure solution of butyl-PBD at a concentration of 4-8 $\mathrm{g} / \mathrm{L}$. Thus, when high counting efficiencies are required, the use of salicylamide as a secondary scintillator can bring substantial savings in the use of expensive heterocyclic primary scintillators

Salicylamide also has potentially important applications as a scintillator and wavelength shifter in the assay of high energy $\beta$-particle emitters, such as ${ }^{32} \mathrm{P}$ or ${ }^{i n} \mathrm{Cl}$, by Cerenkov counting. Recently. salicylic acid was recommended as the best wavelength shifter for Cerenkov scintillation counting. ${ }^{(+1)}$ The counting efficiencies for the Cerenkov counting of ${ }^{36} \mathrm{Cl}$ using salicylamide or salicylic acid are compared in Table 1 , from which it can be seen that very high counting efficiencies are achievable. Even better results may be expected with ${ }^{32} \mathrm{P}$. For example the counting efficiency of a 32P-labelled standard in the dioxane solution of salicylamide exceeded $95^{\circ} \%$.

\section{References}

1. Klöpffer W. Adr. Photochem. 10, 311 (1978).

2. Huppert D., Gutman M. and Kaufmann K. J. Advances in Chemical Physics, Vol. 47. Photoselective Chemistry, Part 2 (Wiley, New York, 1981).

3. Catalan J., Toribio F., Acuna A. U. J. Phys. Chem. 86, 303 (1982) (and references therein)

4. Bem E. M., Bem H. and Reimschüssel W. J. Radioanal. Chem. 79, 69 (1983). 